Published in final edited form as:

Arthritis Care Res (Hoboken). 2020 January ; 72(1): 9-17. doi:10.1002/acr.23824.

\title{
Risk of Hospitalized Infection and Initiation of Abatacept versus TNF Inhibitors among Patients with Rheumatoid Arthritis: a Propensity Score-Matched Cohort Study
}

\author{
Sarah K. Chen, MD ${ }^{1}$, Katherine P. Liao, MD, MPH ${ }^{1}$, Jun Liu, MD, MPH², Seoyoung C. Kim, \\ $\mathrm{MD}, \mathrm{ScD}^{1,2}$ \\ ${ }^{1}$ Division of Rheumatology, Immunology and Allergy, Department of Medicine, Brigham and \\ Women's Hospital, Harvard Medical School, Boston, MA, USA \\ ${ }^{2}$ Division of Pharmacoepidemiology and Pharmacoeconomics, Department of Medicine, Brigham \\ and Women's Hospital, Harvard Medical School, Boston, MA, USA
}

\begin{abstract}
Objective-We aimed to evaluate the comparative risk of hospitalized infection among patients with rheumatoid arthritis (RA) who initiated abatacept versus a TNF inhibitor (TNFi).
\end{abstract}

\begin{abstract}
Methods-We identified RA patients aged $\geq 18$ years with $\geq 2$ RA diagnoses who initiated abatacept or a TNFi using claims data from Truven MarketScan database (2006-2015). The primary outcome was a composite endpoint of any hospitalized infection. Secondary outcomes were bacterial infection, herpes zoster, and infections affecting different organ systems. We performed 1:1 propensity score (PS) matching between the groups to control for baseline confounders. We estimated incidence rates (IR) and hazard ratio (HR) with 95\% confidence intervals (CI) for hospitalized infection.
\end{abstract}

Results-We identified 11,248 PS-matched pairs of abatacept and TNFi initiators with median age of 56 years, and $83 \%$ female sex. The IR per 1,000 person-years for any hospitalized infection was 37 among abatacept initiators and 47 in TNFi initiators. The HR for the risk of any hospitalized infection associated with abatacept versus TNFi was 0.78 (95\% CI 0.64-0.95) and remained lower when compared to infliximab (HR 0.63, 95\% CI 0.47-0.85), while no significant difference was seen compared with adalimumab and etanercept. The risk of secondary outcomes was lower for abatacept for pulmonary infections, and similar to TNFi for the remaining outcomes.

Contact information: Seoyoung C. Kim, MD, ScD, corresponding author Pharmacoepidemiology and Pharmacoeconomics, Brigham and Women's Hospital, 1620 Tremont Street, Suite 3030, Boston, MA 02120, USA, sykim@ @wh.harvard.edu. AUTHOR CONTRIBUTIONS

All authors were involved in drafting the article or revising it critically for important intellectual content, and all authors approved the final version to be submitted for publications. Drs. Chen and Kim had full access to all of the data in the study and take responsibility for the integrity for the data and the accuracy of the data analysis.

Study conception and design:

Chen, Liao, Liu, Kim

Acquisition of data:

Chen, Liu, Kim

Analysis and interpretation of data:

Chen, Liao, Liu, Kim 
Conclusions-In this large cohort of RA patients who used abatacept or TNFi as a first or second-line biologic agent, we found a lower risk of hospitalized infection after initiating abatacept versus TNFi which was driven mostly by infliximab.

Rheumatoid arthritis (RA) patients are at increased risk of infection compared to non-RA patients $^{1-3}$. Part of this elevated risk is secondary to RA disease and due to the impaired ability of the immune system to recognize and fight off infections $s^{4,5}$. While new immunosuppressive therapies have led to dramatic improvements in controlling RA disease activity and damage, the risk of infection is further increased by immunosuppression, especially with the use of biologic disease-modifying anti-rheumatic drugs (DMARDs) ${ }^{6,7}$. Tumor necrosis factor inhibitors (TNFi) and abatacept are both biologic DMARDs, used either as monotherapy or in combination with a nonbiologic DMARD, with comparable efficacy in the treatment of $\mathrm{RA}^{8}$. However, the two therapies may differ in the risk of infection with their use.

Infections are frequent adverse events associated with TNFi therapy in RA and the risk of infection with TNFi use is higher than with non-biologic DMARD use ${ }^{6,9,10}$. While randomized clinical trial data for abatacept did not demonstrate increased risk of serious infections compared to placebo initially, subsequent studies have reported increased incidence of serious infections with its use, with reported IR for infection of 3.1 per 100patient years ${ }^{11-15}$ Although this rate is lower than the reported IR for TNFi of 6 per 100 patient-years ${ }^{6}$, there is a paucity of studies that have compared the two therapies directly. To date, no randomized clinical trial has compared the risk of infections between the different biologic therapies in RA. Previous observational studies have compared the risk of infections between abatacept and TNFi with mixed results ${ }^{16-19}$. While some of these studies have demonstrated a lower risk of infection with abatacept, in one study the risk was similar between abatacept and $\mathrm{TNFi}^{18}$.

Given similar efficacy between abatacept and TNFi as biologic therapies for treatment of RA, one of the main determinants in choosing between the medications is minimizing the risk of infection. Therefore, the aim of this study was to compare the risk of hospitalized infections among RA patients who initiate abatacept versus TNFi in the real-world setting using a large US nationwide claims database. We hypothesized that the rates and risk of hospitalized infection would be lower among RA patients initiating abatacept compared to TNFi.

\section{METHODS}

\section{Data Source and Cohort Definitions}

We used de-identified medical and pharmacy claims data from the Truven MarketScan database (1/1/2006-9/30/2015), which contains longitudinal, comprehensive healthcare data for mostly commercially insured individuals in the U.S. from all 50 states $^{20}$.

We identified RA patients ages 18 and older with at least 2 RA International Classification of Diseases, $9^{\text {th }}$ revision (ICD-9) codes (714.xx) separated by 7-365 days ${ }^{21}$. Among these RA patients, we selected new users of abatacept or TNFi (adalimumab, certolizumab, 
etanercept, golimumab, and infliximab) by the National Drug Codes or J codes, with no dispensing of the medication during at least 365 days of continuous enrollment preceding the date of first dispensing (i.e., index date) of abatacept or TNFi. Patients were required to have the second RA diagnosis code on or before the index date. A diagram of cohort and study design is presented in Supplemental Figure S1. For abatacept initiators, we allowed patients to have used non-biologic DMARDs or TNFi during the baseline period. For TNFi initiators, we allowed patients to have used non-biologic DMARDs or abatacept during the baseline period. We excluded patients who used rituximab, tocilizumab or tofacitinib prior to the index date from the two groups, as the use of other biologic DMARDs could affect the risk of infection during follow-up. We also excluded patients with malignancy, renal dialysis, HIV/AIDS, and history of solid or bone marrow transplantation at baseline, as these are other known comorbidities that would increase the risk of infection.

Study patients were followed from the day following index date, until the earliest event of death, end of enrollment, switching of therapy from abatacept to TNFi or from TNFi to abatacept or outcome occurrence. In our primary analysis, we censored patients using astreated analysis which used a threshold of less than 30 days of treatment or dispensing gap. In a separate sensitivity analysis, we allowed for any gap in treatment and censored patients at the last drug available date.

\section{Data Collection}

During the 365-day period prior to the index date, we collected baseline covariates that may be related to infectious risk including demographics (age, sex, calendar year of index date, region of residence), comorbidities including hypertension, diabetes, obesity, smoking, alcohol use, depression, cardiovascular disease, chronic renal disease, chronic liver disease, pulmonary disease, viral hepatitis, inflammatory bowel disease, hospitalization for infection by ICD-9 codes, and calculated combined comorbidity index at baseline ${ }^{22}$. We measured healthcare utilization characteristics including number of outpatient physician visits to primary care providers and specialists, emergency department visits, acute care hospitalizations, history of influenza vaccination and pneumonia vaccination, and number of unique generic drug prescriptions at baseline.

We assessed use of non-biologic DMARDs including methotrexate, hydroxychloroquine, leflunomide, sulfasalazine, cyclosporine, tacrolimus, azathioprine, auranofin, and penicillamine. We also measured glucocorticoid use as any recent use in 30 days prior to the index date, any use during 365 days prior to the index date, and cumulative prednisoneequivalent dose for 365 days baseline period, calculated based on the total amount in milligrams of prednisone prescribed. We assessed any baseline use of non-steroidal antiinflammatory drugs (NSAIDs), COX-2 enzyme inhibitors (COXIBs), and proton-pump inhibitors. We also assessed use of opioids, antibiotics, and zoster treatment during the 365 days of baseline, and recent use within 30 days prior to the index date.

\section{Outcomes}

The primary outcome was the composite end point of any hospitalized infection including bacterial, viral or opportunistic infection based on the principal diagnosis for hospitalization. 
We assessed secondary outcomes of bacterial infection, herpes zoster, and infections by affected organ system (bone/joint, cardiac, gastrointestinal, genitourinary, respiratory, skin/ soft tissue, neurologic), based on the principal diagnosis for hospitalization. We used ICD-9 codes to identify hospitalized infection as previously described, with positive predictive value $>80 \% 16,23-25$.

\section{Statistical Methods}

We compared the baseline characteristics of the abatacept and TNFi cohorts. To control for over 40 potential confounders simultaneously, we generated propensity score (PS) for the predicted probability of a patient initiating abatacept versus TNFi given patient characteristics at baseline. We then performed a 1:1 PS nearest neighbor matching using a caliper of 0.025 on the PS scale ${ }^{26}$. We compared the covariate balance after matching using standardized differences, and considered the absolute standard mean difference of $<0.1$ as balanced between the two matched groups ${ }^{27}$. After PS matching, we estimated the incidence rates (IR) of the primary and secondary outcomes per 1,000 person-years in the two treatment groups. We used Cox proportional hazards models to estimate the hazard ratios (HR) and 95\% confidence intervals (CI) for primary and secondary outcomes. We ensured the proportional hazards assumption was not violated by including the interaction term of exposure medication and survival time as a time-dependent covariate in our Cox model.

We performed separate PS matching for abatacept versus the 3 most commonly prescribed TNFi (adalimumab, etanercept and infliximab) and calculated the IR per 1,000 person-years and HR for the primary outcome of any hospitalized infection. In another sensitivity analysis, we identified and PS-matched patients who were treatment naïve and had not received either TNFi or abatacept in the baseline period and calculated the IR and HR for primary and secondary outcomes.

All analyses were conducted using SAS 9.4 (SAS Institute, Cary, NC). The Institutional Review Board of the Brigham and Women's Hospital approved this study.

\section{RESULTS}

We identified 13,015 RA patients who were new initiators of abatacept and 52,719 RA patients who were new initiators of TNFi (Figure 1). After 1:1 PS matching, there were 11,248 pairs of patients initiating abatacept and TNFi. Baseline covariates were balanced after PS matching with absolute standardized mean difference $<0.1$. Prior to matching, the abatacept cohort was slightly older $(54.8 \pm 12.8$ vs $52.1 \pm 12.8)$ with a higher proportion of females (83\% vs 76\%) (Table 1). After PS matching, the abatacept cohort had a mean age of $55.3 \pm 12.8$ with $83 \%$ females, and TNFi cohort had a mean age of $55.5 \pm 12.7$ with $84 \%$ females.

The prevalence of several comorbidities was slightly higher among the abatacept cohort including diabetes, hypertension, cardiovascular disease, pulmonary disease but was well balanced between the two cohorts after PS matching. The combined comorbidity score was also higher among the abatacept cohort compared to the TNFi cohort $(0.54 \pm 1.38$ vs 0.38 $\pm 1.18)$, and after PS matching was similar between the two cohorts $(0.57 \pm 1.42$ vs 0.58 
\pm 1.43 ). Measures of healthcare utilization were also generally higher in the abatacept cohort but was balanced after PS matching. Baseline hospitalized infection prevalence was 3\% for both PS matched cohorts.

Use of RA-related medication was well-balanced between the PS matched cohorts, although prior to matching there was a lower prior use of methotrexate, hydroxychloroquine, and sulfasalazine in the abatacept cohort (Table 2). Steroid use was prevalent among both cohorts at 30 days prior to the index date (44\% for abatacept, $42 \%$ for TNFi), and at 365 days prior ( $70 \%$ vs $69 \%$ ). Notably, the $58 \%$ of the abatacept cohort had prescription dispensing for TNFi in the baseline period, compared to $4 \%$ of TNFi cohort patients who had prescription dispensing for abatacept.

The overall IR of the primary outcome for the composite endpoint of any hospitalized infections in our PS matched cohorts was 36.7 per 1,000 person-years (95\% CI 31.8-42.3) for abatacept compared to 47.4 per 1,000 person-years (95\% CI 41.5-54.1) for TNFi using as-treated analysis allowing for $<30$ days gap in treatment (Table 3 ). In the primary astreated analysis allowing for $<30$ days gap in treatment, the mean follow-up time on active treatment was $0.46 \pm 0.70$ years for the abatacept group, and $0.41 \pm 0.66$ years for the TNFi group. The risk of hospitalized infection in abatacept was lower compared to TNFi initiators with a HR of 0.78 (95\% CI 0.64-0.95).

In our PS matched sensitivity analyses between abatacept and the 3 most common TNFi, we found that the HR remained decreased for abatacept compared to infliximab (HR 0.63, 95\% CI 0.47-0.85), but not statistically significantly higher or lower when compared to adalimumab (HR 0.78, 95\% CI 0.57-1.06) and etanercept (HR 1.19, 95\% CI 0.92-1.53)

(Table 4). In a separate sensitivity analysis using as-treated analysis allowing for any gap in treatment the risk of infection was attenuated towards the null. When we broadened our outcome definition of infections using diagnosis codes at any position and not limited to the principal diagnosis code for hospitalization, the results were similar with $\mathrm{HR}$ of infection for abatacept compared to TNFi of 0.79 (95\% CI 0.68-0.92). In secondary analyses assessing risk of separate types of infections, the HR was lower for respiratory infections among abatacept initiators compared to TNFi (Table 5). However, there was no significant difference in the risk of the other types of infections between the abatacept and TNFi cohorts.

As our abatacept initiator could have been treated with TNFi previously, and TNFi initiators could similarly have been treated with abatacept, we conducted sensitivity analysis for our primary and secondary outcomes for only patients who were treatment naïve to both therapies during the baseline period (Supplemental Table S1). After PS-matching we identified 4,574 treatment-naïve abatacept initiators and equal number of TNFi initiators. The HR for any hospitalized infection for abatacept compared to TNFi was 0.87 (95\% CI $0.68-1.11)$. 


\section{DISCUSSION}

RA patients are at increased risk of infections and this risk is further increased with use of immunosuppressive therapy. Whether there is a difference in infectious risk conferred by different biologic DMARDs is unclear. In this US nationwide study of RA patients, we found that the IR and risk of hospitalized infections were lower among patients initiating abatacept compared to TNFi. This difference in risk appears to be mostly driven by lower infection risk when compared to infliximab. In our secondary outcome analysis, risk of respiratory infections (e.g., pneumonia, empyema, upper respiratory tract infections) was also lower among patients in the abatacept cohort compared to the TNFi cohort. However, there was no significant difference in the risk of hospitalized infections by the remaining types of infections or by affected organ systems.

The IR for infections found in our study are similar to what has been reported for abatacept and TNFi in the literature, with reported IR for abatacept of 31 per 1,000 person-years, and 60 per 1,000 person-years for TNFi in separate studies ${ }^{6,13}$. Further, the results are in line with most of the other studies that have compared the risk of infection between abatacept and TNFi. In a previous cohort study using Truven MarketScan data comparing the risk of infections in RA patients switching from first-line TNFi to rituximab, another TNFi or abatacept, the risk of infection was similar after switching to abatacept versus rituximab ${ }^{19}$. However, the infection risk was higher for those switching to another TNFi compared to rituximab. Similarly, a cohort study in Medicare data with RA patients who were previously treated with a biologic agent and newly switching to a different TNFi, rituximab,

tocilizumab or abatacept found that the risk of one-year hospitalized infection was higher in the etanercept (HR 1.24, 95\% CI 1.07-1.45), infliximab (HR 1.39, 95\% CI 1.21-1.60) and rituximab (HR 1.36, 95\% CI 1.21-1.53) groups compared to abatacept as reference ${ }^{17}$.

In another previous study using administrative claims data from 2005-2009, among RA patients who were initiating or switching biologic DMARD therapy, abatacept users had lower rates of hospitalized infection compared to infliximab (HR 0.68, 95\% CI 0.48-0.96) ${ }^{16}$. The risk of infection was also lower for adalimumab and etanercept compared to infliximab in that study, while in our study we observed a lower infection risk for abatacept compared to infliximab (HR $0.63,95 \%$ CI 0.47-0.85), a numerically lower risk for abatacept compared to adalimumab (HR $0.78,95 \%$ CI $0.57-1.06$ ), and similar risk for abatacept compared to etanercept (see Table 4).

In a predominantly male RA cohort of US veterans from 1998-2011, the risk of hospitalized bacterial infections was similar between abatacept compared to etanercept (HR 1.1, 95\% CI $0.6-21$ ), with IR for abatacept of 28 per 1,000 person-years (95\% CI 17-47) ${ }^{18}$. These rates are in line with the hospitalized bacterial infection IR of 19.4 per 1,000 person-years (95\% CI 15.9-23.6), and HR 0.81 (95\% CI 0.62-1.06) in our study. Additionally, similar to our study results, previous reports comparing the risk of herpes zoster infections found no difference in the risk of zoster infections between abatacept and TNFi, with the IR of zoster infections slightly higher in previously reported literature for abatacept (IR 23.3 per 1,000 person-years, 95\% CI 20.4-26.7 in one study ${ }^{28}$, and IR 18.7 per 1,000 person-years, 95\% CI 
15.8-22.0 in another ${ }^{29}$ ) compared to our study IR of 15.7 per 1,000 person-years (95\% CI 12.7-19.6) in abatacept and 15.7 per 1,000 person-years (95\% CI 12.5-19.8) in TNFi.

In our separate analysis comparing the risk of hospitalized infection in abatacept initiators versus the three most commonly prescribed TNFi, we found that the lower risk of hospitalized infection in abatacept initiators compared to TNFi was driven mostly by infliximab initiators (HR $0.63,95 \%$ CI $0.47-0.85$ ). The risk remained numerically, not statistically significantly, lower for abatacept in comparison to adalimumab initiators (HR $0.78,95 \% 0.57-1.06$ ), but the infection risk associated with abatacept was noted to be not significantly higher versus etanercept (HR 1.19, 95\% CI 0.92-1.53). These results are in line with previously reported lower risk of serious infections in patients treated with etanercept compared to infliximab and adalimumab in a prospective cohort of RA patients in a Dutch registry ${ }^{30}$. There are several potential explanations for this observed difference among TNFi. The peak concentration of infliximab which is delivered as an intravenous infusion is higher than that of adalimumab and etanercept which are administered as subcutaneous injections ${ }^{31}$. Additionally, the clearance of etanercept is significantly higher with lower steady-state drug level compared to infliximab and adalimumab, and the binding avidity to TNF subunits is lower for etanercept (1:1 ratio), compared to infliximab (up to 3:1 ratio $)^{31,32}$. Furthermore, etanercept is a TNF receptor fusion protein that binds only circulating TNF while infliximab is a monoclonal antibody against TNF and additionally has a cytotoxic effect by binding to cells that express TNF on their membranes ${ }^{33}$.

Our study has several strengths as a large cohort of US patients with RA in a nationwide database with a new user design with active comparator. In comparison to the previously mentioned studies, we used PS matching to minimize confounding by indication and control for imbalance among the abatacept and TNFi treatment groups to including patient characteristics, regional variation and adjusted for a large number of baseline confounders between the two cohorts such as prior antibiotic and antiviral use, and history of vaccinations. We directly compared the IR and risk of infection between abatacept and TNFi inhibitors and found lower IR of infections for abatacept compared to TNFi, similar to the reported IR in the literature, and lower risk of infection among abatacept initiators. The reason for this decreased risk of infection found in our study and previous studies is unknown but may potentially be due to the fact that abatacept indirectly blocks T-cell costimulation rather than the mechanism of directly inhibiting cytokines for $\mathrm{TNFi}^{11}$.

In a separate analysis using as-treated analysis allowing for any gap in treatment, there was no significant difference in risk of infection between the abatacept and TNFi cohorts. In our primary analysis, we used an as-treated analysis with $<30$ days of gap in treatment which requires high treatment adherence. Using this design, we observed a lower risk of hospitalized infection in abatacept initiators. This suggests that there may be selection bias for patients who are more adherent or continued on therapy versus those who discontinue their therapy for those on abatacept versus TNFi. Although it is not possible to ascertain the reasons for stopping the therapy after initiation using claims databases, one possibility is that there is a lower threshold to stop or switch from TNFi therapy if there was concern of risk of infection such as minor infections which may lower the rates of hospitalized infections for TNFi compared to abatacept. 
It is notable that in our study which examined first-line or subsequent-line initiators of abatacept or TNFi, 58\% of the abatacept cohort was previously on TNFi in the baseline period and would be classified as switchers, compared to only $4 \%$ of TNFi cohort who had previously used abatacept. In our sensitivity analysis, among patients who were treatment naïve to both abatacept and TNFi, the lower risk of infection among abatacept initiators compared to TNFi was attenuated toward the null. This suggests a potential role of RA disease severity of treatment history in addition to the types of biologics on the risk of infection in RA patients.

Our study has limitations. Although we used PS matching for confounding control, there is still a concern for partially measured covariates and lack of information on other covariates that may affect risk of infection. For instance, RA disease activity is an important factor that can affect the risk of infections ${ }^{34}$, but is a covariate we are unable to capture in a claims database $^{35-38}$. Therefore, we included measures of steroid use, non-biologic DMARD use, number of rheumatology visits, and combined comorbidity index as covariates in our PSmatching. Steroid use was a covariate in our analysis, is another important factor in risk of infections and may be indirectly related to disease activity. However, there may be discrepancies between steroid dispensing measured in our study and actual use by patients ${ }^{39-41}$. We also attempted to assess sero-status as a covariate were limited by power as less than $3 \%$ of patients in each cohort had available laboratory results. Additionally, socioeconomic status and race and ethnicity are important demographic factors in the US that contribute to health disparities and outcomes that we were unable to collect and adjust for in our study ${ }^{42,43}$.

In this large nationwide cohort of RA patients in the U.S. initiating abatacept or a TNFi as a first- or second-line biologic therapy, we found a lower risk of any hospitalized infections associated with abatacept versus TNFi, particularly in comparison to infliximab, suggesting that RA patients with specific concerns about infections may benefit from use of abatacept compared to TNFi.

\title{
Supplementary Material
}

Refer to Web version on PubMed Central for supplementary material.

\section{Acknowledgments}

\author{
SOURCES OF FUNDING
}

This study was funded by an investigator-sponsored research grant from Bristol-Myers Squibb. The funding sources played no role in the study design, data analysis or interpretation of data or presentation of results. The funder was given the opportunity to make non-binding comments on a draft of the manuscript, but the authors retained the right of publication and to determine the final wording.

DISCLOSURES

SK Chen is supported by NIH Institutional Training Grant (T32 AR 7530-33).

KP Liao is supported by the Harold and DuVal Bowen Fund,

SC Kim received research support from Bristol-Myers Squibb, Roche, and Pfizer to the Brigham and Women's Hospital. 
J Liu has nothing to disclose.

\section{REFERENCES}

1. Doran MF, Crowson CS, Pond GR, O'Fallon WM, Gabriel SE. Frequency of infection in patients with rheumatoid arthritis compared with controls: a population-based study. Arthritis Rheum 2002;46(9):2287-2293. [PubMed: 12355475]

2. Mitchell DM, Spitz PW, Young DY, Bloch DA, McShane DJ, Fries JF. Survival, prognosis, and causes of death in rheumatoid arthritis. Arthritis Rheum 1986;29(6):706-714. [PubMed: 3718563]

3. Smitten AL, Choi HK, Hochberg MC, Suissa S, Simon TA, Testa MA, Chan KA. The risk of hospitalized infection in patients with rheumatoid arthritis. J Rheumatol 2008;35(3):387-393. [PubMed: 18260176]

4. Mikuls TR. Co-morbidity in rheumatoid arthritis. Best Pract Res Clin Rheumatol 2003;17(5):729752. [PubMed: 12915155]

5. Wagner UG, Koetz K, Weyand CM, Goronzy JJ. Perturbation of the T cell repertoire in rheumatoid arthritis. Proc Natl Acad Sci U S A 1998;95(24):14447-14452. [PubMed: 9826720]

6. Listing J, Strangfeld A, Kary S, Rau R, von Hinueber U, Stoyanova-Scholz M, Gromnica-Ihle E, Antoni C, Herzer P, Kekow J, Schneider M, Zink A. Infections in patients with rheumatoid arthritis treated with biologic agents. Arthritis Rheum 2005;52(11):3403-3412. doi:10.1002/art.21386 [PubMed: 16255017]

7. Ruderman EM. Overview of safety of non-biologic and biologic DMARDs. Rheumatology 2012;51(suppl 6):vi37-vi43. [PubMed: 23221586]

8. Curtis JR, Singh JA. Use of Biologics in Rheumatoid Arthritis: Current and Emerging Paradigms of Care. Clin Ther 2011;33(6):679-707. [PubMed: 21704234]

9. Strangfeld A, Listing J, Herzer P, Liebhaber A, Rockwitz K, Richter C, Zink A. Risk of herpes zoster in patients with rheumatoid arthritis treated with anti-TNF-alpha agents. JAMA 2009;301(7): 737-744. [PubMed: 19224750]

10. Kroesen S, Widmer AF, Tyndall A, Hasler P. Serious bacterial infections in patients with rheumatoid arthritis under anti-TNF-alpha therapy. Rheumatology (Oxford) 2003;42(5):617-621. [PubMed: 12709536]

11. Genovese MC, Becker J-C, Schiff M, Luggen M, Sherrer Y, Kremer J, Birbara C, Box J, Natarajan K, Nuamah I, Li T, Aranda R, Hagerty DT, Dougados M. Abatacept for rheumatoid arthritis refractory to tumor necrosis factor alpha inhibition. N Engl J Med 2005;353(11):1114-1123. [PubMed: 16162882]

12. Salliot C, Dougados M, Gossec L. Risk of serious infections during rituximab, abatacept and anakinra treatments for rheumatoid arthritis: meta-analyses of randomised placebo-controlled trials. Ann Rheum Dis 2009;68(1):25-32. [PubMed: 18203761]

13. Simon TA, Askling J, Lacaille D, Franklin J, Wolfe F, Covucci A, Suissa S, Hochberg MC, Abatacept Epidemiology Study Group. Infections requiring hospitalization in the abatacept clinical development program: an epidemiological assessment. Arthritis Res Ther 2010;12(2):R67. [PubMed: 20398273]

14. Weinblatt M, Combe B, Covucci A, Aranda R, Becker JC, Keystone E. Safety of the selective costimulation modulator abatacept in rheumatoid arthritis patients receiving background biologic and nonbiologic disease-modifying antirheumatic drugs: A one-year randomized, placebocontrolled study. Arthritis Rheum 2006;54(9):2807-2816. [PubMed: 16947384]

15. Kremer JM, Genant HK, Moreland LW, Russell AS, Emery P, Abud-Mendoza C, Szechinski J, Li T, Ge Z, Becker J-C, Westhovens R. Effects of abatacept in patients with methotrexate-resistant active rheumatoid arthritis: a randomized trial. Ann Intern Med 2006;144(12):865-876. [PubMed: 16785475]

16. Curtis JR, Xie F, Chen L, Baddley JW, Beukelman T, Saag KG, Spettell C, McMahan RM, Fernandes J, Winthrop K, Delzell E. The comparative risk of serious infections among rheumatoid arthritis patients starting or switching biological agents. Ann Rheum Dis 2011;70(8):1401-1406. [PubMed: 21586439] 
17. Yun H, Xie F, Delzell E, Levitan EB, Chen L, Lewis JD, Saag KG, Beukelman T, Winthrop KL, Baddley JW, Curtis JR. Comparative Risk of Hospitalized Infection Associated With Biologic Agents in Rheumatoid Arthritis Patients Enrolled in Medicare. Arthritis Rheumatol 2016;68(1): 56-66. [PubMed: 26315675]

18. Curtis JR, Yang S, Patkar NM, Chen L, Singh JA, Cannon GW, Mikuls TR, Delzell E, Saag KG, Safford MM, DuVall S, Alexander K, Napalkov P, Winthrop KL, Burton MJ, Kamauu A, Baddley JW. Risk of Hospitalized Bacterial Infections Associated With Biologic Treatment Among US Veterans With Rheumatoid Arthritis. Arthritis Care Res (Hoboken) 2014;66(7):990-997. [PubMed: 24470378]

19. Johnston SS, Turpcu A, Shi N, Fowler R, Chu B-C, Alexander K. Risk of infections in rheumatoid arthritis patients switching from anti-TNF agents to rituximab, abatacept, or another anti-TNF agent, a retrospective administrative claims analysis. Semin Arthritis Rheum 2013;43(1):39-47. [PubMed: 23453683]

20. Desai RJ, Rao JK, Hansen RA, Fang G, Maciejewski M, Farley J. Tumor Necrosis Factor- Inhibitor Treatment and the Risk of Incident Cardiovascular Events in Patients with Early Rheumatoid Arthritis: A Nested Case-control Study. J Rheumatol 2014;41(11):2129-2136. [PubMed: 25086079]

21. Kim S, Servi A, Polinski J. Validation of rheumatoid arthritis diagnoses in health care utilization data. Arthritis Res Ther 2011;13(1):R32. [PubMed: 21345216]

22. Gagne JJ, Glynn RJ, Avorn J, Levin R, Schneeweiss S. A combined comorbidity score predicted mortality in elderly patients better than existing scores. J Clin Epidemiol 2011;64(7):749-759. [PubMed: 21208778]

23. Curtis JR, Xie F, Yun H, Saag KG, Chen L, Delzell E. Risk of hospitalized infection among rheumatoid arthritis patients concurrently treated with a biologic agent and denosumab. Arthritis Rheumatol (Hoboken, NJ) 2015;67(6):1456-1464.

24. Schneeweiss S, Robicsek A, Scranton R, Zuckerman D, Solomon DH. Veteran's affairs hospital discharge databases coded serious bacterial infections accurately. J Clin Epidemiol 2007;60(4): 397-409. [PubMed: 17346615]

25. Patkar NM, Curtis JR, Teng GG, Allison JJ, Saag M, Martin C, Saag KG. Administrative codes combined with medical records based criteria accurately identified bacterial infections among rheumatoid arthritis patients. J Clin Epidemiol 2009;62(3):321-327.e7. [PubMed: 18834713]

26. Ripollone JE, Huybrechts KF, Rothman KJ, Ferguson RE, Franklin JM. Implications of the Propensity Score Matching Paradox in Pharmacoepidemiology. Am J Epidemiol 2018;187(9): 1951-1961. [PubMed: 29750409]

27. Austin PC. Using the Standardized Difference to Compare the Prevalence of a Binary Variable Between Two Groups in Observational Research. Commun Stat - Simul Comput 2009;38(6):12281234. doi:10.1080/03610910902859574

28. Curtis JR, Xie F, Yun H, Bernatsky S, Winthrop KL. Real-world comparative risks of herpes virus infections in tofacitinib and biologic-treated patients with rheumatoid arthritis. Ann Rheum Dis 2016;75(10):1843-1847. doi:10.1136/annrheumdis-2016-209131 [PubMed: 27113415]

29. Yun H, Xie F, Delzell E, Chen L, Levitan EB, Lewis JD, Saag KG, Beukelman T, Winthrop K, Baddley JW, Curtis JR. Risks of Herpes Zoster in Patients With Rheumatoid Arthritis According to Biologic Disease-Modifying Therapy. Arthritis Care Res (Hoboken) 2015;67(5):731-736. doi: 10.1002/acr.22470 [PubMed: 25201241]

30. van Dartel SAA, Fransen J, Kievit W, Flendrie M, den Broeder AA, Visser H, Hartkamp A, van de Laar MAFJ, van Riel PLCM. Difference in the risk of serious infections in patients with rheumatoid arthritis treated with adalimumab, infliximab and etanercept: results from the Dutch Rheumatoid Arthritis Monitoring (DREAM) registry. Ann Rheum Dis 2013;72(6):895-900. [PubMed: 22887849]

31. Furst DE, Wallis R, Broder M, Beenhouwer DO. Tumor Necrosis Factor Antagonists: Different Kinetics and/or Mechanisms of Action May Explain Differences in the Risk for Developing Granulomatous Infection. Semin Arthritis Rheum 2006;36(3):159-167. [PubMed: 16884970]

32. Scallon B, Cai A, Solowski N, Rosenberg A, Song X-Y, Shealy D, Wagner C. Binding and functional comparisons of two types of tumor necrosis factor antagonists. J Pharmacol Exp Ther 2002;301(2):418-426. [PubMed: 11961039] 
33. Scallon BJ, Moore MA, Trinh H, Knight DM, Ghrayeb J. Chimeric anti-TNF-alpha monoclonal antibody cA2 binds recombinant transmembrane TNF-alpha and activates immune effector functions. Cytokine 1995;7(3):251-259. [PubMed: 7640345]

34. Au K, Reed G, Curtis JR, Kremer JM, Greenberg JD, Strand V, Furst DE, CORRONA Investigators. High disease activity is associated with an increased risk of infection in patients with rheumatoid arthritis. Ann Rheum Dis 2011;70(5):785-791. [PubMed: 21288960]

35. Wolfe F, Michaud K, Simon T. Can severity be predicted by treatment variables in rheumatoid arthritis administrative data bases? J Rheumatol 2006;33(10):1952-1956. [PubMed: 16960927]

36. Ting G, Schneeweiss S, Scranton R, Katz JN, Weinblatt ME, Young M, Avorn J, Solomon DH. Development of a health care utilisation data-based index for rheumatoid arthritis severity: a preliminary study. Arthritis Res Ther 2008;10(4):R95. [PubMed: 18717997]

37. Desai RJ, Solomon DH, Weinblatt ME, Shadick N, Kim SC. An external validation study reporting poor correlation between the claims-based index for rheumatoid arthritis severity and the disease activity score. Arthritis Res Ther 2015;17(1):83. [PubMed: 25880932]

38. Vinet E, Kuriya B, Widdifield J, Bernatsky S. Rheumatoid Arthritis Disease Severity Indices in Administrative Databases: A Systematic Review. J Rheumatol 2011;38(11):2318-2325. [PubMed: 21921094]

39. Saag KG, Koehnke R, Caldwell JR, Brasington R, Burmeister LF, Zimmerman B, Kohler JA, Furst DE. Low dose long-term corticosteroid therapy in rheumatoid arthritis: an analysis of serious adverse events. Am J Med 1994;96(2):115-123. [PubMed: 8109596]

40. Doran MF, Crowson CS, Pond GR, O'Fallon WM, Gabriel SE. Predictors of infection in rheumatoid arthritis. Arthritis Rheum 2002;46(9):2294-2300. [PubMed: 12355476]

41. Schneeweiss S, Setoguchi S, Weinblatt ME, Katz JN, Avorn J, Sax PE, Levin R, Solomon DH. Anti-tumor necrosis factor a therapy and the risk of serious bacterial infections in elderly patients with rheumatoid arthritis. Arthritis Rheum 2007;56(6):1754-1764. [PubMed: 17530704]

42. Kawachi I, Daniels N, Robinson DE. Health disparities by race and class: why both matter. Health Aff (Millwood) 2005;24(2):343-352. [PubMed: 15757918]

43. Betancourt JR, Green AR, Carrillo JE, Ananeh-Firempong O. Defining cultural competence: a practical framework for addressing racial/ethnic disparities in health and health care. Public Health Rep 2003;118(4):293-302. [PubMed: 12815076] 


\section{Significance and Innovation}

- $\quad$ Comparative safety of infection risk associated with biologic immunosuppression with TNF inhibitors versus abatacept in RA patients is unclear

- In this propensity score-matched study of 11,248 pairs of RA patients initiating abatacept or TNF inhibitor, the incidence rate and risk of hospitalized infections were lower among abatacept initiators (HR 0.78, 95\% CI 0.64-0.95)

- In subgroup analysis, the risk of infection for abatacept remained lower when compared to infliximab initiators, but not for etanercept and abatacept initiators

- Use of abatacept is associated with a lower risk of hospitalized infections compared to TNF inhibitors among RA patients, in particular when compared to infliximab. 


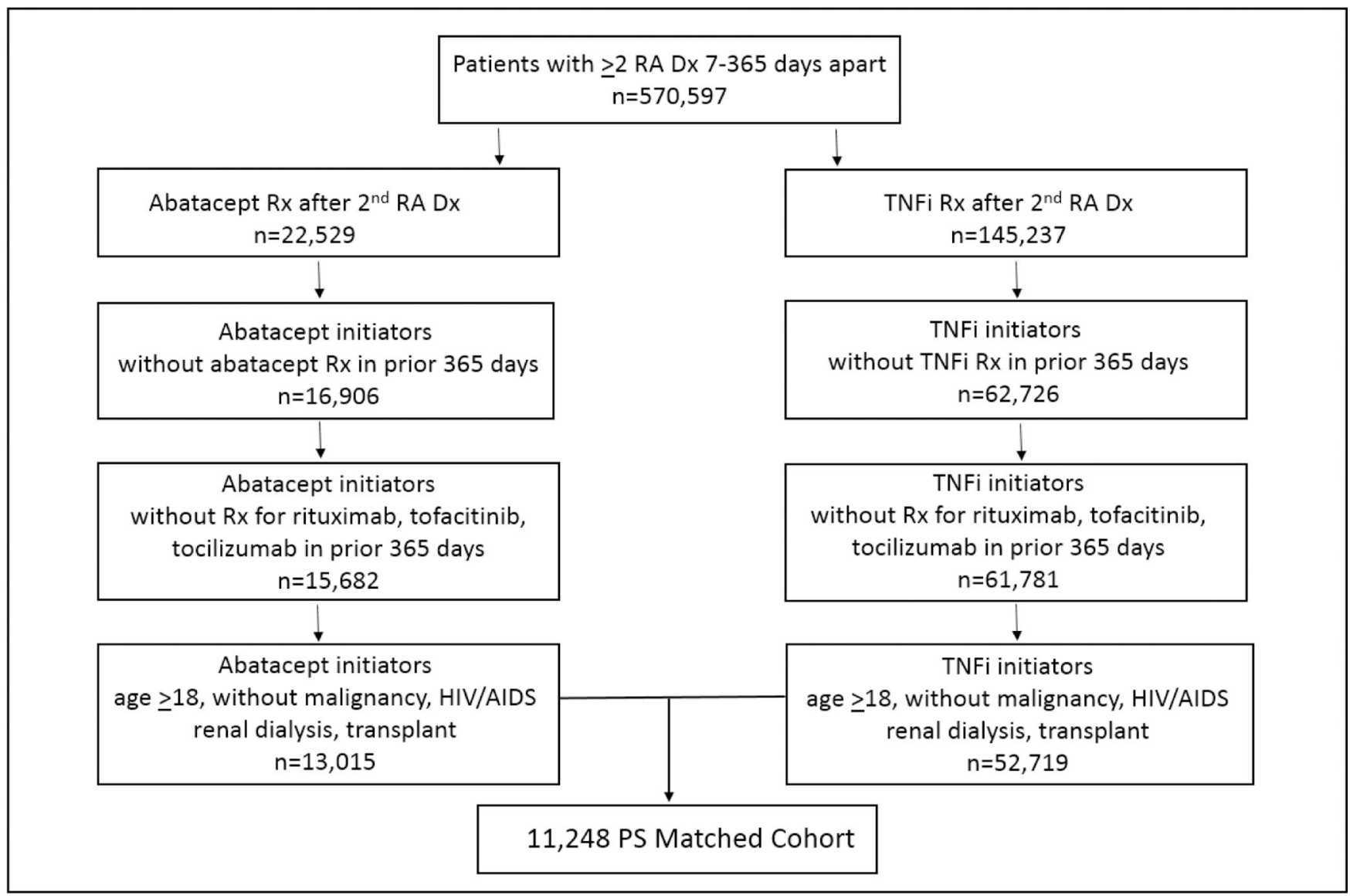

RA: rheumatoid arthritis; Dx: diagnosis; TNFi: TNF inhibitor; PS: propensity score

Figure 1. Flow chart of study cohort selection

RA: rheumatoid arthritis; Dx: diagnosis; TNFi: TNF inhibitor; PS: propensity score 
Table 1.

Baseline characteristics of study cohorts, prior to and after 1:1 propensity score-matching

\begin{tabular}{|c|c|c|c|c|}
\hline & \multicolumn{2}{|c|}{ Prior to matching } & \multicolumn{2}{|c|}{ Propensity score-matched } \\
\hline & Abatacept & TNFi & Abatacept & TNFi \\
\hline & $\mathrm{N}=13,015$ & $\mathrm{~N}=52,719$ & $\mathrm{~N}=11,248$ & $\mathrm{~N}=11,248$ \\
\hline \multicolumn{5}{|l|}{ Demographics } \\
\hline Mean age (SD), years & $54.8(12.8)$ & $52.1(12.8)$ & $55.3(12.8)$ & $55.5(12.7)$ \\
\hline Female sex & $83 \%$ & $76 \%$ & $83 \%$ & $84 \%$ \\
\hline \multicolumn{5}{|l|}{ Region } \\
\hline Northeast & $13 \%$ & $14 \%$ & $13 \%$ & $13 \%$ \\
\hline South & $39 \%$ & $40 \%$ & $39 \%$ & $39 \%$ \\
\hline North central & $21 \%$ & $22 \%$ & $21 \%$ & $21 \%$ \\
\hline West & $15 \%$ & $16 \%$ & $15 \%$ & $15 \%$ \\
\hline Unknown & $11 \%$ & $9 \%$ & $12 \%$ & $12 \%$ \\
\hline \multicolumn{5}{|l|}{ Comorbidities } \\
\hline Obesity & $9 \%$ & $9 \%$ & $9 \%$ & $9 \%$ \\
\hline Smoking & $12 \%$ & $12 \%$ & $12 \%$ & $13 \%$ \\
\hline Alcohol use & $1 \%$ & $1 \%$ & $1 \%$ & $1 \%$ \\
\hline Depression & $12 \%$ & $11 \%$ & $12 \%$ & $12 \%$ \\
\hline Diabetes & $17 \%$ & $15 \%$ & $18 \%$ & $18 \%$ \\
\hline Hypertension & $42 \%$ & $37 \%$ & $43 \%$ & $43 \%$ \\
\hline Hyperlipidemia & $32 \%$ & $30 \%$ & $32 \%$ & $32 \%$ \\
\hline Cardiovascular disease & $56 \%$ & $49 \%$ & $57 \%$ & $57 \%$ \\
\hline Heart failure & $4 \%$ & $2 \%$ & $4 \%$ & $5 \%$ \\
\hline Pulmonary disease & $19 \%$ & $16 \%$ & $20 \%$ & $20 \%$ \\
\hline Chronic kidney disease & $4 \%$ & $3 \%$ & $4 \%$ & $4 \%$ \\
\hline Chronic liver disease & $5 \%$ & $5 \%$ & $5 \%$ & $5 \%$ \\
\hline Viral hepatitis & $1 \%$ & $1 \%$ & $1 \%$ & $1 \%$ \\
\hline Inflammatory bowel disease & $1 \%$ & $3 \%$ & $1 \%$ & $1 \%$ \\
\hline Hospitalized infection & $3 \%$ & $2 \%$ & $3 \%$ & $3 \%$ \\
\hline Mean combined comorbidity score (SD) & $0.54(1.38)$ & $0.38(1.18)$ & $0.57(1.42)$ & $0.58(1.43)$ \\
\hline \multicolumn{5}{|l|}{ Healthcare utilization } \\
\hline Mean No. PCP visits (SD) & $6.1(7.8)$ & $5.3(6.5)$ & $6.1(7.9)$ & $6.1(7.9)$ \\
\hline Mean No. Rheumatology visits (SD) & $4.5(4.7)$ & $3.4(3.7)$ & $4.4(4.7)$ & $4.2(4.7)$ \\
\hline ED visits & $31 \%$ & $28 \%$ & $31 \%$ & $31 \%$ \\
\hline Any hospitalization & $17 \%$ & $13 \%$ & $18 \%$ & $18 \%$ \\
\hline Mean No. unique prescriptions & $14.4(8.2)$ & $13.2(7.5)$ & $14.1(8.3)$ & $14.1(8.2)$ \\
\hline Flu vaccination & $30 \%$ & $25 \%$ & $29 \%$ & $29 \%$ \\
\hline Pneumonia vaccination & $7 \%$ & $8 \%$ & $7 \%$ & $7 \%$ \\
\hline
\end{tabular}


Table 2.

Baseline medications of study cohorts, prior to and after 1:1 propensity score-matching

\begin{tabular}{|c|c|c|c|c|}
\hline & \multicolumn{2}{|c|}{ Prior to matching } & \multicolumn{2}{|c|}{ Propensity score-matched } \\
\hline & Abatacept & TNFi & Abatacept & TNFi \\
\hline & $\mathrm{N}=13,015$ & $\mathrm{~N}=52,719$ & $\mathrm{~N}=11,248$ & $\mathrm{~N}=11,248$ \\
\hline \multicolumn{5}{|l|}{ Prior use of biologic DMARDs } \\
\hline Abatacept & $0 \%$ & $2 \%$ & $0 \%$ & $4 \%$ \\
\hline TNFi & $64 \%$ & $0 \%$ & $58 \%$ & $0 \%$ \\
\hline Adalimumab & $24 \%$ & $0 \%$ & $16 \%$ & $0 \%$ \\
\hline Certolizumab & $4 \%$ & $0 \%$ & $2 \%$ & $0 \%$ \\
\hline Etanercept & $24 \%$ & $0 \%$ & $16 \%$ & $0 \%$ \\
\hline Golimumab & $4 \%$ & $0 \%$ & $3 \%$ & $0 \%$ \\
\hline Infliximab & $21 \%$ & $0 \%$ & $20 \%$ & $0 \%$ \\
\hline \multicolumn{5}{|l|}{ Prior use of non-biologic DMARDs } \\
\hline Methotrexate & $56 \%$ & $69 \%$ & $55 \%$ & $55 \%$ \\
\hline Hydroxychloroquine & $23 \%$ & $27 \%$ & $23 \%$ & $23 \%$ \\
\hline Leflunomide & $18 \%$ & $14 \%$ & $18 \%$ & $18 \%$ \\
\hline Sulfasalazine & $9 \%$ & $12 \%$ & $9 \%$ & $8 \%$ \\
\hline Other $^{*}$ & $8 \%$ & $5 \%$ & $8 \%$ & $8 \%$ \\
\hline \multicolumn{5}{|l|}{ Steroid use } \\
\hline Steroid use & $70 \%$ & $69 \%$ & $68 \%$ & $67 \%$ \\
\hline Recent steroid use (30 days prior) & $44 \%$ & $42 \%$ & $43 \%$ & $43 \%$ \\
\hline Mean steroids cumulative dose 365 days in $\mathrm{mg}$ (SD) & $1235.9(3484.3)$ & $1184.7(9042.6)$ & $1192.9(3572.8)$ & $1191.6(6178.4)$ \\
\hline \multicolumn{5}{|l|}{ Other Medications } \\
\hline Antibiotics & $69 \%$ & $64 \%$ & $69 \%$ & $68 \%$ \\
\hline Recent antibiotics ( 30 days prior) & $19 \%$ & $16 \%$ & $19 \%$ & $19 \%$ \\
\hline Antiviral for zoster & $8 \%$ & $6 \%$ & $8 \%$ & $8 \%$ \\
\hline Recent antiviral for zoster & $3 \%$ & $2 \%$ & $3 \%$ & $3 \%$ \\
\hline NSAIDs & $44 \%$ & $54 \%$ & $43 \%$ & $42 \%$ \\
\hline COXIBs & $11 \%$ & $11 \%$ & $11 \%$ & $11 \%$ \\
\hline Opioids & $68 \%$ & $64 \%$ & $67 \%$ & $67 \%$ \\
\hline Recent opioids ( 30 days prior) & $40 \%$ & $33 \%$ & $39 \%$ & $40 \%$ \\
\hline Proton-pump inhibitors & $30 \%$ & $26 \%$ & $30 \%$ & $30 \%$ \\
\hline
\end{tabular}

Other non-biologic DMARDs: cyclosporine, tacrolimus, azathioprine, auranofin, penicillamine 
Table 3.

Risk of hospitalized infection in abatacept versus TNFi initiators: 1:1 PS-matched analysis

\begin{tabular}{|c|c|c|c|c|c|c|c|c|}
\hline & \multicolumn{4}{|c|}{ Abatacept $(\mathrm{N}=\mathbf{1 1 , 2 4 8 )}$} & \multicolumn{4}{|c|}{ TNFi $(\mathrm{N}=11,248)$} \\
\hline & No. Events & $\begin{array}{l}\text { Person- } \\
\text { Years }\end{array}$ & $\begin{array}{l}\text { IR, per } 1000 \mathrm{PY} \\
(95 \% \mathrm{CI})\end{array}$ & $\operatorname{HR}(95 \% \mathrm{CI})$ & No. Events & $\begin{array}{l}\text { Person- } \\
\text { years }\end{array}$ & $\begin{array}{l}\text { IR, per } 1000 \mathrm{PY} \\
(95 \% \mathrm{CI})\end{array}$ & $\begin{array}{l}\mathrm{HR}(95 \% \\
\mathrm{CI})\end{array}$ \\
\hline $\begin{array}{l}\text { As-Treated } \\
(<30 \text { days } \\
\text { gap) }\end{array}$ & 188 & 5,126 & $\begin{array}{c}36.7(31.8- \\
42.3)\end{array}$ & $\begin{array}{c}0.78(0.64- \\
0.95)\end{array}$ & 219 & 4,621 & $\begin{array}{c}47.4(41.5- \\
54.1)\end{array}$ & 1.0 \\
\hline $\begin{array}{l}\text { As-Treated } \\
\text { (Any gap) }\end{array}$ & 298 & 8,201 & $\begin{array}{c}36.3(32.4- \\
40.7)\end{array}$ & $\begin{array}{c}0.86(0.74- \\
1.01)\end{array}$ & 321 & 7,639 & $\begin{array}{c}42.0(37.7- \\
46.9)\end{array}$ & 1.0 \\
\hline
\end{tabular}




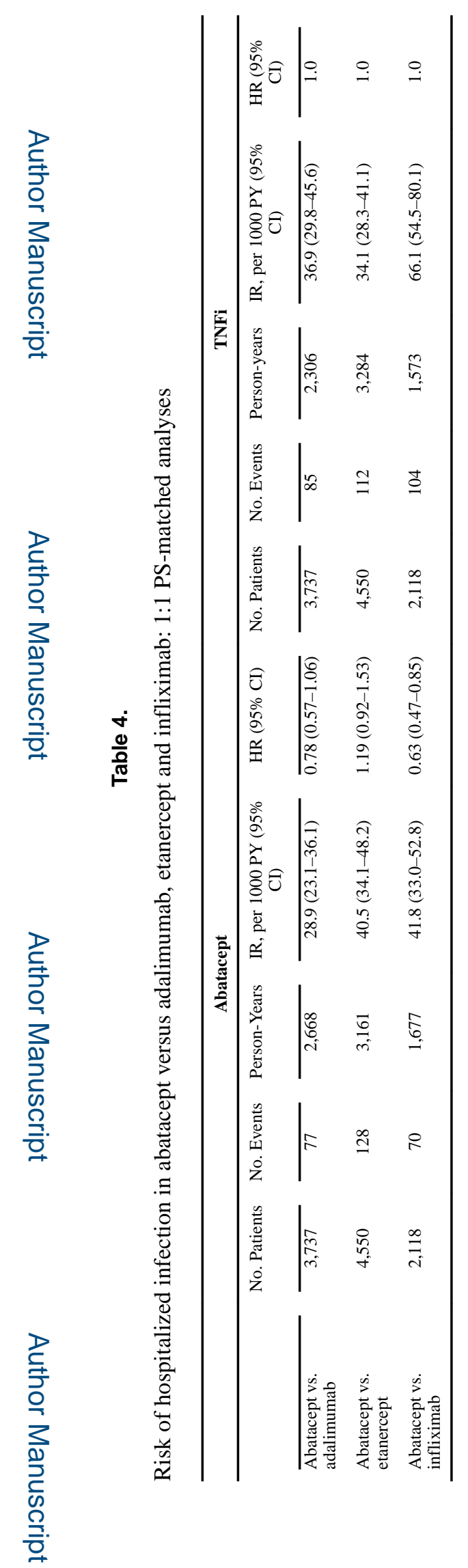

Arthritis Care Res (Hoboken). Author manuscript; available in PMC 2021 January 01. 
Table 5.

Risk of secondary outcomes for abatacept versus TNFi initiators: 1:1 PS-matched analysis for as-treated $(<30$ days gap)

\begin{tabular}{|c|c|c|c|c|c|c|c|c|}
\hline & \multicolumn{4}{|c|}{ Abatacept $(\mathrm{N}=\mathbf{1 1 , 2 4 8})$} & \multicolumn{4}{|c|}{ TNFi (N=11,248) } \\
\hline & $\begin{array}{l}\text { No. } \\
\text { Events }\end{array}$ & $\begin{array}{l}\text { Person- } \\
\text { Years }\end{array}$ & $\begin{array}{l}\text { IR, per } 1000 \\
\text { PY }(95 \% \text { CI) }\end{array}$ & HR $(95 \% \mathrm{CI})$ & $\begin{array}{l}\text { No. } \\
\text { Events }\end{array}$ & $\begin{array}{l}\text { Person- } \\
\text { years }\end{array}$ & $\begin{array}{l}\text { IR, per } 1000 \\
\text { PY }\end{array}$ & $\begin{array}{l}\mathrm{HR}(95 \% \\
\mathrm{CI})\end{array}$ \\
\hline$\overline{\text { Bacterial infection }}$ & 100 & 5,160 & $\begin{array}{l}19.4(15.9- \\
23.6)\end{array}$ & $\begin{array}{c}0.81(0.62- \\
1.06)\end{array}$ & 112 & 4,621 & $\begin{array}{l}24.0(20.0- \\
28.9)\end{array}$ & 1.0 \\
\hline Herpes zoster & 81 & 5,141 & $\begin{array}{l}15.8(12.7- \\
19.6)\end{array}$ & $\begin{array}{c}1.00(0.73- \\
1.37)\end{array}$ & 73 & 4,639 & $\begin{array}{l}15.7(12.5- \\
19.8)\end{array}$ & 1.0 \\
\hline \multicolumn{9}{|l|}{$\overline{\text { By organ system }}$} \\
\hline Bone/Joint & 7 & 5,190 & $1.4(0.6-2.8)$ & $\begin{array}{c}0.91(0.32- \\
2.60)\end{array}$ & 7 & 4,696 & $1.5(0.7-3.1)$ & 1.0 \\
\hline Cardiac & 0 & 5,191 & - & - & 1 & 4,697 & $0.2(<0.1-1.5)$ & 1.0 \\
\hline Gastrointestinal & 20 & 5,186 & $3.9(2.5-6.0)$ & $\begin{array}{c}0.75(0.41- \\
1.35)\end{array}$ & 24 & 4,689 & $5.1(3.4-7.6)$ & 1.0 \\
\hline Genitourinary & 17 & 5,185 & $3.3(2.0-5.3)$ & $\begin{array}{c}1.04(0.52- \\
2.07)\end{array}$ & 15 & 4,690 & $3.2(1.9-5.3)$ & 1.0 \\
\hline Respiratory & 65 & 5,160 & $\begin{array}{c}12.6(9.9- \\
16.1)\end{array}$ & $\begin{array}{c}0.71(0.52- \\
0.99)\end{array}$ & 83 & 4,666 & $\begin{array}{l}17.8(14.4- \\
22.1)\end{array}$ & 1.0 \\
\hline Skin/soft tissue & 30 & 5,179 & $5.8(4.1-8.3)$ & $\begin{array}{c}0.68(0.42- \\
1.09)\end{array}$ & 40 & 4,683 & $8.5(6.3-11.6)$ & 1.0 \\
\hline Neurologic & 1 & 5,191 & $0.2(<0.1-1.4)$ & $\begin{array}{c}0.91(0.06- \\
14.5)\end{array}$ & 1 & 4,697 & $0.2(<0.1-1.5)$ & 1.0 \\
\hline
\end{tabular}

